\title{
Design of reinforced concrete buildings according to the new NEHRP provisions
}

\author{
O. A. Mohamed \& P. Khamwan \\ Department of Civil, Biomedical and Environmental Engineering, \\ University of Hartford, West Hartford, USA
}

\begin{abstract}
This paper examines the seismic analysis and design requirements for earthquake resistant reinforced concrete buildings according to the recent NEHRP recommended provisions, also known as FEMA 450. To demonstrate the implementation of the NEHRP provisions, a case study reinforced concrete building is analyzed and designed. A number of key modeling and design considerations are examined such as: (1) the effects of upper and lower limits imposed by the provisions on design fundamental period; (2) the variation of drift along the height of the building in a structure that contains a dual lateral force resisting system in one direction and a moment resisting frame in another direction, compared to the limiting NEHRP value; (3) comparison of the torsional irregularity limit in the provisions to finite element computations for dual lateral resisting system as well as special moment resisting frame system; (4) the effects on structural response of the interaction of shear-wall and special moment resisting concrete frames.
\end{abstract}

Keywords: seismic design, NEHRP provisions, dual systems, torsional irregularity.

\section{Introduction}

The Building Seismic Safety Council (BSSC) of The National Institute of Building Science (NIBS) established the National Earthquake Hazard Reduction Program (NEHRP) more than 25 years ago with the objective of minimizing earthquake hazards and the damage and injury they might cause. The United States Federal Emergency Management Agency (FEMA) has been supporting BSSC through a number of contracts to publish and update documents, such as 
FEMA 450 [1], on the best practices for design of buildings and other structures to mitigate the hazards of earthquakes. Although FEMA 450 is not a general building code, its provisions are incorporated in whole or in part by legally biding codes such as the International Building Code (IBC) [2] and recognized load estimation standards such as ASCE 7 [3] published by the American Society of Civil Engineers. The recommendations of the previous NEHRP provisions are discussed and analyzed elsewhere $[4,5]$. The next NEHRP update is scheduled for publication in 2008 .

This paper explores the analysis and design recommendations for reinforced concrete buildings on the recently published NERHP provisions [1]. A case study reinforced concrete building is analyzed and designed using the Equivalent Lateral Force (ELF) method described in section 5.2 of the NEHRP recommended provisions which will be referred to in this paper as the provisions. The use of the ELF method is limited to structures with regular mass/stiffness/strength properties and when the lateral motions and torsional motion are not strongly coupled. Despite these restrictions, many structures are designed according the ELF method. Furthermore, to determine if a more accurate method, such as nonlinear time history analysis, is necessary, certain quantities will need to be determined and evaluated based on the ELF method.

\section{Description of case study}

The case study is a reinforced concrete building consisting of 13-stories above grade and one story below grade. The plan view of a typical floor is shown in fig. 1. The lateral force resisting system in the North-South (N-S) direction consists of four special moment resisting frames with Response Modification Factor, $\mathrm{R}=8$. Lateral force resistance in the East-West (E-W) direction is provided by a dual system consisting of special moment frames and the shear walls with $\mathrm{R}=8$. The response modification factor is intended to account for damping, overstrength, and ductility present in the system at large displacement. Analysis was done using ETABS software produced and marketed by Computers and Structures, Inc., USA. Site class is C, which represents very dense soil and soft rock with shear wave velocity between $360 \mathrm{~m} / \mathrm{s}$ and $760 \mathrm{~m} / \mathrm{s}$. Seismic Use Group is ' $\mathrm{I}$ ' representing structures other than essential facilities or those having substantial public hazard.

Spectral response acceleration parameter at short periods is $S_{S}=1.65$ and at one second is $S_{1}=0.68$. The design spectral response acceleration parameter at short periods is calculated to be $s_{D s}=1.1$ and at one second is $s_{D 1}=0.589$

The ELF method uses eqn. (1) to calculate fundamental mode base shear force, $\mathrm{V}$, for sustained weight, $\mathrm{W}$.

$$
V=C W
$$

The structure was designed for the seismic forces described above in addition to typical, dead, live, and wind loads to satisfy the requirements of the provisions and ACI 318 [6]. 
(a)

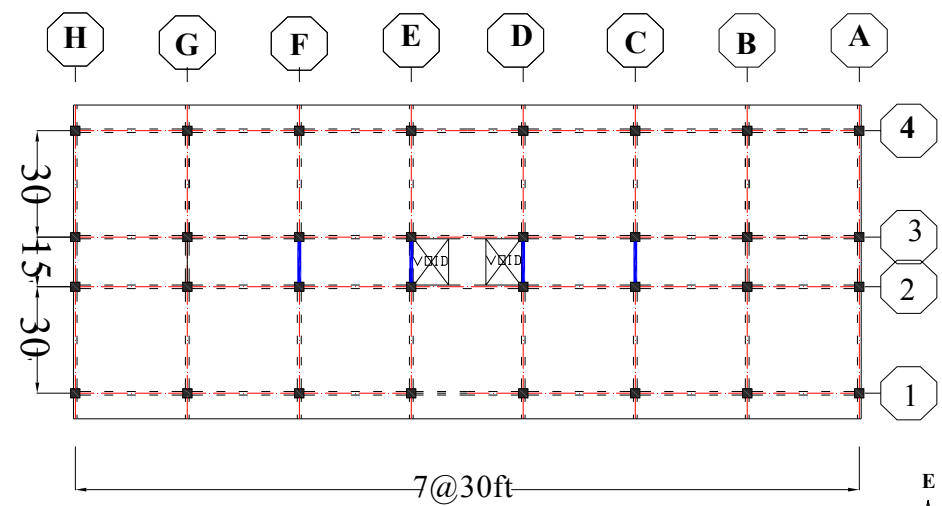

(b)
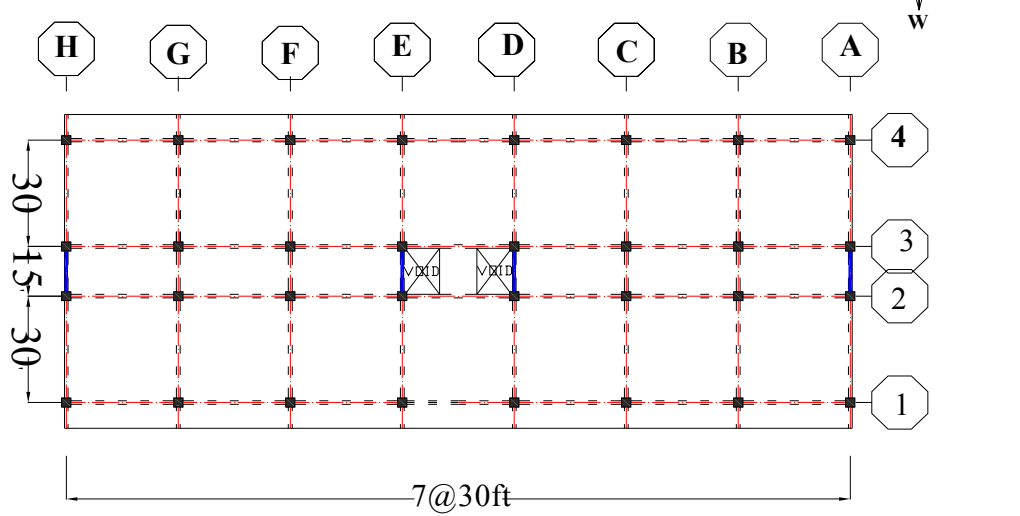

Figure 1: Case study, (a) plan view of the reinforced concrete building (b) alternative shear-walls locations to reduce torsional amplification.

\section{Lower and upper limits on design fundamental period}

The provisions permit the fundamental period to be approximated by eqn. (2),

$$
T_{a}=C_{r} h_{n}^{x}
$$

where,

$C_{r} \& x$ : coefficients that depend on lateral force resisting type, from Table 5.2-2 of the provisions.

$h_{n}$ : building height in feet (meters).

Based on eqn. (2), the special moment resisting frames in N-S direction may be designed for a period $T_{a}=1.51$ seconds and the dual system in the E-W direction may be designed for $T_{a}=0.88$ seconds. 
A finite element analysis shows that the fundamental period in the N-S is $T_{a}=1.89$ seconds and the fundamental period in the $\mathrm{E}-\mathrm{W}$ direction $T_{a}=1.64$ seconds. Clearly, using the provisions approximate periods, which was derived from a lower-bound regression analysis of a number of buildings, produces a conservative design for the system in the N-S direction and even more conservative design in the E-W direction where the dual system is used.

Although the use of more accurate methods for determination of fundamental periods is recommended in the provisions, the value used in design is limited by eqn. (3).

$$
T_{\text {upper }}=C_{u} C_{c r} h_{n}^{x}
$$

The N-S special moment resisting frames upper limit on fundamental period is $T_{\text {upper }}=2.11$ seconds, which is higher than the finite element calculated value of $T_{a}=1.51$ seconds. The E-W dual system upper limit on fundamental period is $T_{\text {upper }}=0.825$ seconds, which is lower than the finite calculated value of $T_{a}=0.88$ seconds. Therefore, in this case study, the provisions impose a penalty on the dual system, which leads to a rather conservative design, while no such penalty is imposed on the special moment resisting frame. According to section 5.2.2 of the provisions, the designer is allowed to use analysis-based fundamental period that is no more than $40 \%$ to $70 \%$ of the approximate fundamental period estimated by eqn. (2). This depends on the magnitude of the design spectral response acceleration parameter at a period of one second, $S_{D 1}$.

\section{Drift resistance by special moment frames compared to dual systems}

Drift calculated using elastic analysis based on the ELF method should be magnified by certain prescribed factors to account for the fact that during a design seismic event, a structure may deform beyond the elastic limit. The amplification factor for the dual system in the E-W direction is $C_{d}=6.5$ and for the special moment frame in the $\mathrm{N}-\mathrm{S}$ direction is $C_{d}=5.5$, according to Table 4.3-1 of the provisions. All members contributing to lateral resistance in the E-W and N-S directions were assumed to be cracked and the upper limit on fundamental period described in section 3 of this paper was not considered as permitted by the provisions. The calculated and magnified drifts are shown in fig. 2, together with the maximum permissible drift. For this case study structure, which belongs to Seismic Use Group I, the maximum permissible drift at any level is $2 \%$ of the building height below that level. This structure meets drift limitations in both directions.

The magnified drifts shown in the N-S moment resisting frames tends to curve up near the top story while the magnified drifts in the E-W dual system tends to flatten toward the top story. The flattening of the drift curve in the E-W is caused by the interaction between the shear walls and the moment resisting frames. As a result of shear-wall frame interaction exhibited by the drift curve, the in-plane shears in the frames do not differ significantly from story to another. 
This helps keep shear design uniform, which could potentially contribute to reducing the labour part of the construction cost.

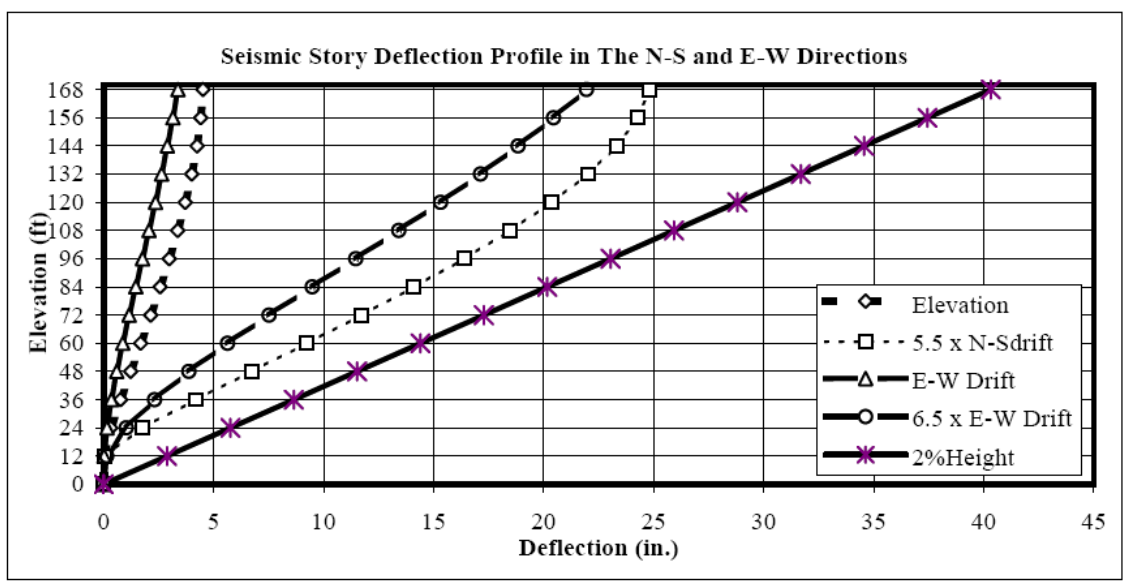

Figure 2: Calculated and magnified drifts in the E-W and N-S directions, compared to the maximum permissible drift.

\section{Dynamic amplification due to torsional effects}

A structure that is irregular in plan could experience amplification of lateral deformation due to torsion during a seismic event. Section 5.2.4.3 of the provisions requires that inherent torsional moment of the structure, $M_{t}$, and accidental torsion moment, $M_{t a}$, be magnified by the dynamic amplification factor is given by eqn. (4), when the lateral forces in members are calculated. This condition applies to structures that fall in Seismic Design Categories, C, D, $\mathrm{E}$, and $\mathrm{F}$.

$$
A_{x}=\left(\frac{\delta_{\max }}{1.2 \delta_{\text {avg }}}\right)^{2}
$$

$\delta_{\max }=$ the maximum displacement at Level $x$, and

$\delta_{\text {avg }}=$ the average of the displacements at the extreme points of the structure at Level $x$.

The mass and lateral force resisting elements in the E-W and N-S directions are distributed such that $M_{t}=0$, however, $M_{t a}$ caused by lateral loads applied at $5 \%$ of the dimension of the structure from the centre of mass, must be considered per section 5.2.4.2 of the provisions. According to eqn. (4), dynamic 
amplification is not necessary when $\frac{\delta_{\max }}{\delta_{\text {avg }}} \leq 1.2$. Analysis of the structure shown in fig. 1(a) produces the ratio $\delta_{\max } / \delta_{\text {avg }}$ shown on fig. 3. Clearly, dynamic amplification of accidental torsion is not necessary in the N-S direction. However, in the E-W direction, where the aspect ratio of the building in plan view is large, dynamic amplification of accidental torsion is necessary. This is the case even though the shear walls are stiffening the building in the E-W direction resulting in reduced deformations compared to the $\mathrm{N}-\mathrm{S}$ direction as shown in fig. 2.

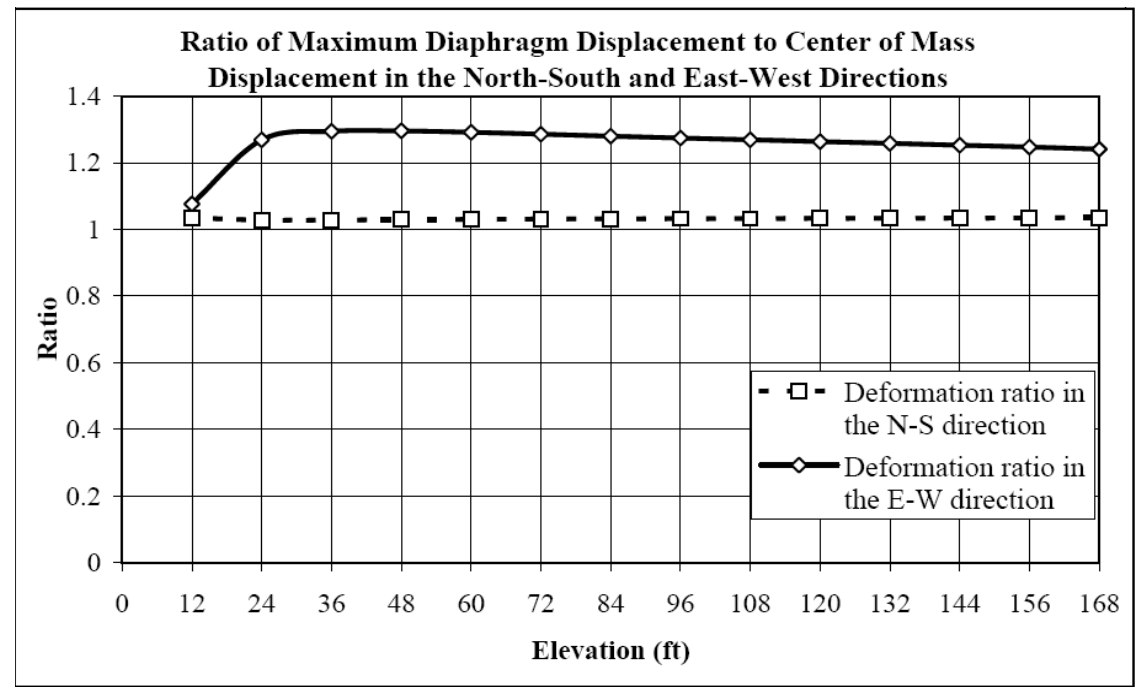

Figure 3: Ratio of maximum diaphragm displacement to centre of mass displacement in the E-W and N-S directions for the shear walls configuration shown in fig. 1(a).

As an alternative to amplification of accidental torsion in the E-W direction as suggested by fig. 3, the two outer shear walls are removed and placed at the extreme ends of the building parallel to the E-W direction, between grid lines 3 and 4, as shown in fig. 1(b). Analysis of the structure in fig. 1(b) shows that placing the outer shear walls at the extreme ends of the building increases Torsional resistance and reduces the diaphragm deformation ratio such $\frac{\delta_{\text {max }}}{\delta_{\text {avg }}}<1.2$, as shown in fig. 4. Therefore, dynamic amplification of accidental torsion in the E-W direction will not occur. 


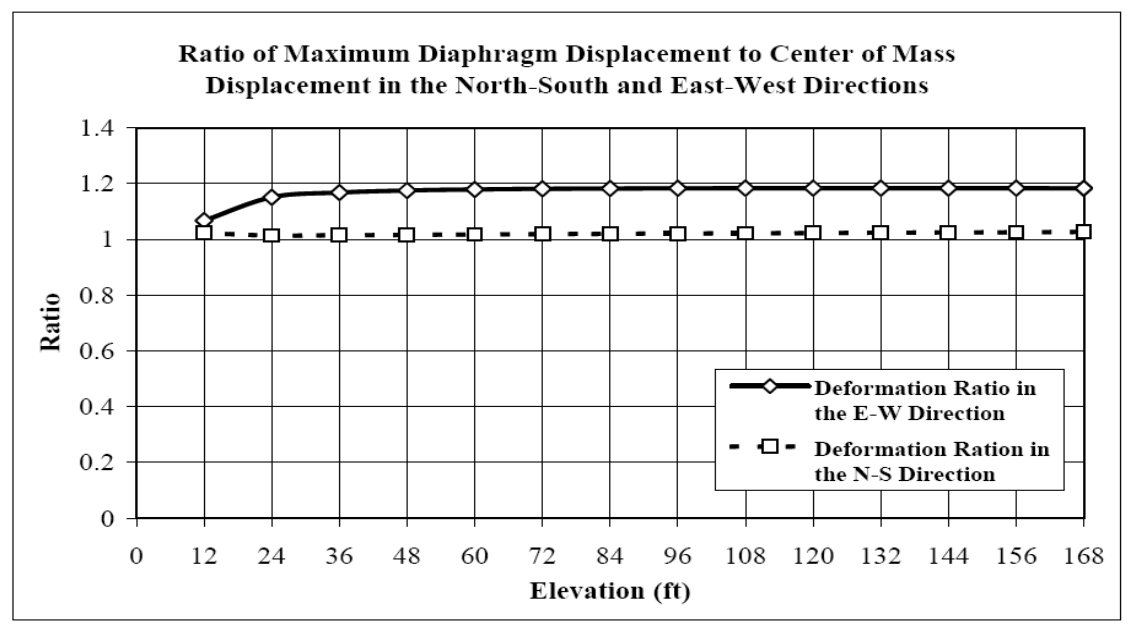

Figure 4: Ratio of maximum deformation to centre of mass deformation in the E-W and N-S directions is reduced below the dynamic amplification limit for the structure in fig. 1(b).

\section{Interaction between shear-walls and moment resisting frames}

The dual system of shear-walls and special moment resisting frames located in the E-W direction of the structure has positive effects in the structural response. As shown in fig. 5, the frames that did not include shear walls, namely, Frame A and Frame B, attracted less lateral shear compared to Frame C, which contained a shear-wall. The balance of the shear force in the plane of Frame $\mathrm{C}$ was attracted by the shear- wall. However, beams in the frames that do not contain shear-walls in the E-W direction produces in-plane shear forces that do not differ greatly from story to another [5]. This provides opportunity for economic design with reduced/variation in shear design of beams.

Section 5.2.5 of the provisions requires that the structure at each story level be capable of resisting overturning moments calculated according to eqn. (5).

$$
M_{x}=\sum_{i=x}^{n} F_{i}\left(h_{i}-h_{x}\right)
$$

where,

$h_{i} \& h_{x}$ : height from base to level $i$ or $x$.

$F_{i}$ : the portion of the seismic base shear, $\mathrm{V}$, introduced at level $i$.

For the dual system in the E-W direction, the interaction of shear walls with moment frames reduces overturning moments in the frames due, in part, to the out-rigger effects of the E-W spanning beams on each side of the shear-wall. As shown in fig. 6, Frame C, located in the plane that contains a shear-wall experienced reduced overturning moments compared to Frames A and B which 
lie in planes that do not contain shear-walls. However as demonstrated elsewhere [5], frames that do not contain shear-walls but located in load direction that contains shear walls, also gain the benefit of reduced overturning moments compared similar frames located on a load direction that contains only moment resisting frames without any shear walls.

\section{Frame A}

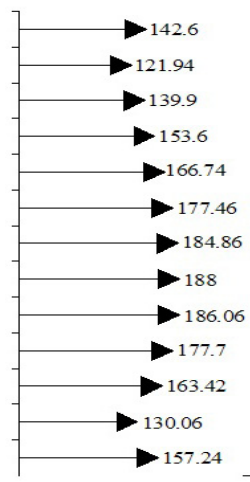

Frame B

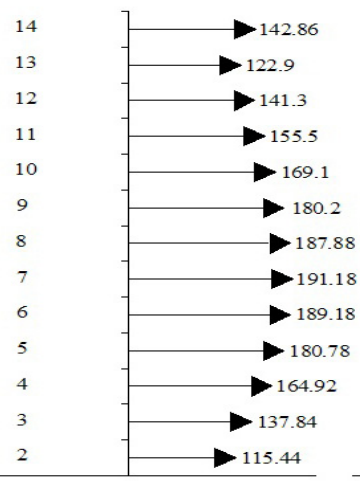

Frame C

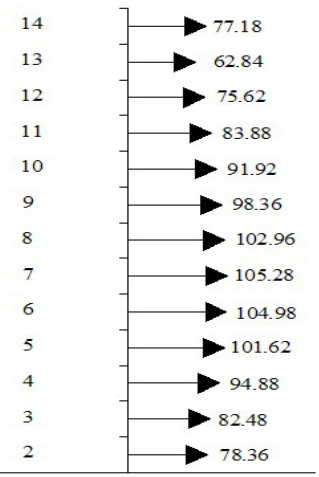

Figure 5: Frame shear forces in the E-W direction. Frames A and B do not contain shear-walls. Frame C contains shear-walls.

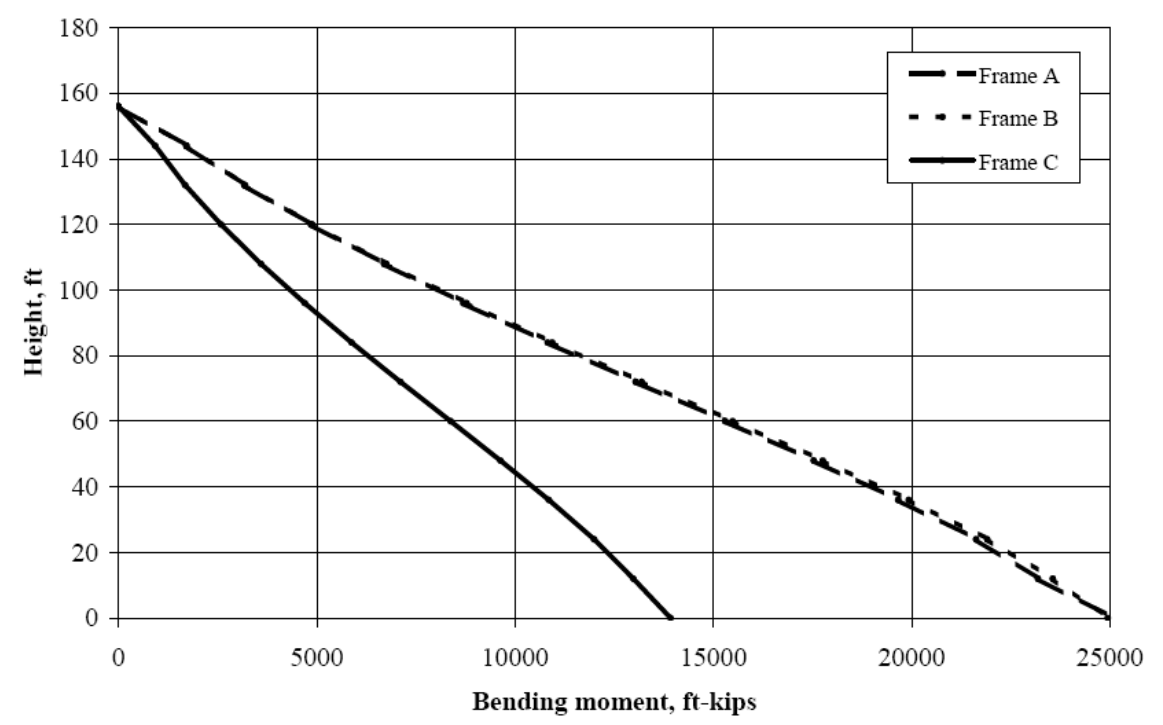

Figure 6: Overturning moments in the E-W direction. Frames $\mathrm{A}$ and $\mathrm{B}$ experienced higher overturning moments than Frame C. 


\section{Summary and conclusions}

- Even structures that are regular both with respect to distribution of stiffness and mss may still experience excessive drift due to accidental torsion when the plan aspect ratio is large. The provisions require that dynamic effects of torsion to be considered in the calculation of loads distributed to structural elements.

- It is possible to reduce drift caused by excessive accidental torsion by placing the lateral force resisting elements judicially away from the geometric centroid of the floors.

- Dual lateral force resisting systems consisting of shear walls and special moment frames produces lateral deflection profile that is relatively flat instead of the typical curves characteristic of cantilever shear walls or shear dominated curves of special moment frames. As a result, the in-plane shear forces of the frames that do not include shear walls do not differ significantly along the height of the structures. This can lead to relatively uniform shear design.

- Dual lateral force resisting system consisting of shear walls and special moment frames experience lower overturning moments at the special moment frames containing the shear walls, especially with long span girders because of outrigger effects.

\section{References}

[1] United States Federal Emergency Management Agency. NEHRP Recommended Provisions for Seismic Regulations for New Buildings and other Structures - FEMA 450, Prepared by the National Institute of Building Science, Washington DC, USA, 2003.

[2] International Code Council. 2006 International Building Code, Washington DC, 2006.

[3] American Society of Civil Engineers. ASCE 7-05 - Minimum Design Loads for Buildings and other Structures, Reston, VA.

[4] Mohamed, O. A. Exploration of the FEMA368 Guidelines for the Seismic Design of Reinforced Concrete Buildings. Proc. of ERES - fifth International Conference on Earthquake Resistant Engineering Structures, Eds. C.A. Brebbia, D.E. Beskos, G.D. Manolis, and C.C. Spyrakos, WIT Press, Southampton, UK, pp. 765-774, 2005.

[5] United states Federal Emergency Management Agency. Guide Application of 2000 NEHRP Recommended Provisions, FEMA 368, Multihazard Building Design Summer Institute, Emmitsburg, Maryland, 2003.

[6] American Concrete Institute. Building Code Requirements for Structural Concrete (ACI 318-05) and Commentary (ACI 318R-05). Farmington Hills, MI, 2005. 